\title{
Survival Benefit of Locoregional Treatment for Hepatocellular Carcinoma with Advanced Liver Cirrhosis
}

\author{
Satoshi Kitai ${ }^{a}$ Masatoshi Kudo ${ }^{a}$ Naoshi Nishida ${ }^{a}$ Namiki Izumib \\ Michiie Sakamoto ${ }^{c}$ Yutaka Matsuyamad Takafumi Ichidae \\ Osamu Nakashima ${ }^{f}$ Osamu Matsuig Yonson Ku ${ }^{\text {h }}$ Norihiro Kokudo \\ Masatoshi Makuuchij for the Liver Cancer Study Group of Japan \\ aDepartment of Gastroenterology and Hepatology, Kinki University School of Medicine, Osaka- \\ Sayama, 'Department of Gastroenterology and Hepatology, Musashino Red Cross Hospital, 'Depart- \\ ment of Pathology, Keio University School of Medicine, dDepartment of Biostatistics, School of Public \\ Health, University of Tokyo, Tokyo, eShonan-East General Hospital, Kanagawa, fDepartment of Clinical \\ Laboratory Medicine, Kurume University Hospital, Kurume, 9Department of Radiology, Kanazawa \\ University Graduate School of Medical Science, Kanazawa, hDepartment of Surgery, Kobe University \\ Graduate School of Medicine, Kobe, iHepato-Biliary-Pancreatic Surgery Division, Artificial Organ and \\ Transplantation Division, Department of Surgery, Graduate School of Medicine, University of Tokyo, \\ jDepartment of Surgery, Japanese Red Cross Medical Center, Tokyo, Japan
}

\section{Key Words}

Best supportive care $\cdot$ Child-Pugh grade $C \cdot$ Local ablation therapy ·

Transarterial chemoembolization

\begin{abstract}
Background \& Aims: Hepatocellular carcinoma (HCC) with decompensated liver cirrhosis (LC) is a life-threatening condition, which is amenable to liver transplantation (LT) as the standard first-line treatment. However, the application of LT can be limited due to a shortage of donor livers. This study aimed to clarify the effect of non-surgical therapy on the survival of patients with HCC and decompensated LC. Methods: Of the 58,886 patients with HCC registered in the nationwide survey of the Liver Cancer Study Group of Japan (January 2000-December 2005), we included 1,344 patients with primary HCC and Child-Pugh (C-P) grade C for analysis in this retrospective study. Among the patients analyzed, 108 underwent LT, 273 were treated by local ablation therapy (LAT), 370 were treated by transarterial chemoembolization
\end{abstract}


(TACE), and 593 received best supportive care (BSC). The effect of LT, LAT, and TACE on overall survival (OS) was analyzed using multivariate and propensity score analyses. Results: Patient characteristics did not differ significantly between each treatment group and the BSC group, after propensity score matching. LAT (hazard ratio [HR]) $=0.568 ; 95 \%$ confidence interval [CI], $0.40-0.80)$ and TACE (HR=0.691; 95\% CI, 0.50-0.96) were identified as significant contributors to OS if the C-P score was less than 11 and tumor conditions met the Milan criteria. Conclusions: For patients with HCC within the Milan criteria and with a C-P score of 10 or 11 , locoregional treatment can be used as a salvage treatment if LT is not feasible.

Copyright $\odot 2016$ S. Karger AG, Basel

\section{Introduction}

Hepatocellular carcinoma (HCC) is one of the most common malignancies worldwide and the second leading cause of death from cancer [1]. Approximately $80 \%$ of patients with HCC have chronic hepatitis and liver cirrhosis (LC), which is attributed to chronic infection with hepatitis B virus (HBV) and/or hepatitis C virus (HCV) [2]. Despite recent advancements in antiviral therapy for viral hepatitis, the prognosis of patients with decompensated LC remains poor, especially in cases with concomitant HCC [3]. Therefore, in addition to tumor stage, it is critical to evaluate liver function for the management of patients with HCC $[4,5]$.

For HCC with preserved liver function, several treatment options are available including partial hepatectomy [6], liver transplantation (LT) [7-11], local ablation therapy (LAT) [12], and transarterial chemoembolization (TACE) [13-16]. In particular, LT is recommended for patients with advanced LC of Child-Pugh (C-P) grade C and an early stage of HCC $[5,7,10,17]$. However, the application of LT to patients with HCC has been limited because of the shortage of donor livers. In addition, systemic therapies including sorafenib are not feasible without any survival benefit in HCC cases with C-P grade C [18]. Therefore, it is necessary to know whether conventional locoregional treatment for HCC, such as LAT and TACE, can improve survival even in patients with HCC and C-P grade C. However, there has been a lack of evidence for the value of locoregional treatments in such patients with decompensated LC although several reports state some survival benefit in a small-sized retrospective study $[19,20]$. Because best supportive care (BSC) is recommended for patients with HCC and $\mathrm{C}$-P grade $\mathrm{C}$, when LT is not applicable, the benefits of BSC in comparison to locoregional treatments should be assessed in the context of overall survival (OS) in these patients.

We address this important issue using a systematic and multi-pronged approach with a large cohort of patients with HCC and C-P grade C using a Japanese nationwide database. The aim of this study was to evaluate the utility of non-surgical treatment for patients suffering from primary HCC with decompensated LC.

\section{Materials and Methods}

\section{Patient Characteristics}

Patients included in the analysis were registered in the database of a nationwide survey of the Liver Cancer Study Group of Japan (LCSGJ). The data collection and registration of patients with HCC included in this analysis were performed with the approval of each patient's institution. Obtaining informed consent from patients was not required because of the retrospective design of the study.

The patients were diagnosed with HCC on the basis of histological or radiological examinations as well as clinical criteria [5, 21-23]. A histological examination was performed if the tumor did not present 
with typical radiological features or if an increase in any HCC-specific tumor markers (alpha-fetoprotein [AFP], Lens culinaris agglutinin-reactive AFP and des-gamma-carboxy prothrombin) was not detected.

Of the 58,886 patients who were registered in the LCSGJ as having newly diagnosed HCC between January 2000 and December 2005, 42,905 were eligible for this analysis because all of the following data were available in the database including: C-P grade and its constitutive parameters (serum bilirubin level, serum albumin level, prothrombin time (PT), ascites, and hepatic encephalopathy), age, sex, status of HBV and HCV, tumor size, number of tumors, tumor-, node-metastasis (TNM) stage, and treatment modalities (i.e., LT, LAT, TACE, or BSC).

Among them, a total of 1,344 patients were classified as having C-P grade $\mathrm{C}$ and were enrolled in this study. Among the enrolled patients, 656 were identified with a C-P score of 10. Likewise, the numbers of patients with C-P scores of 11,12,13,14, and 15 were 384, 186, 73, 38, and 7, respectively. The diagnosis of HCC was mainly established by imaging studies; 189 out of 1,344 patients were diagnosed by biopsy or via operatively extracted specimens. Tumors of 828 patients were within the Milan criteria, whereas 516 did not meet the criteria. To determine the eligibility for locoregional treatment for HCC according to the C-P score, we further classified cases of HCC into two groups as follows: the 'lower score' group (C-P score $=10$ or $11, n=603$ ) and the "higher score" group (C-P score $=12-15, n=143$ ). There were no patients who were treated with radiofrequency ablation (RFA) combined with TACE in this study. The details of the clinical data of the patients are summarized in the tables 1 and 2.

\section{Statistical Analysis}

First, we determined which factors significantly affected the OS of patients with HCC and C-P grade C. Accordingly, we compared the OS of patients categorized according to clinical background using KaplanMeier analysis, and univariate parameters were analyzed using the log-rank test. Patients were censored at the time of their last clinical visit or death not due to HCC. Variables with a p value of $<0.05$ on univariate analysis were further subjected to the multivariate analysis using the Cox proportional-hazards regression model to determine independent contributors to OS. Patient characteristics were compared among different treatment groups using Pearson's chi-square test for categorical variables and the Student's ttest for continuous variables.

In order to avoid selection bias of the treatment due to the different backgrounds of patients with HCC, we applied propensity score analyses, which allowed the normalization of patients' characteristics between each treatment group. Propensity score analyses were performed for the two group pairs, LAT vs. BSC, and TACE vs. BSC, to evaluate the benefit of treatment in comparison to BSC. The Kaplan-Meier method and log-rank test were also used for survival analyses of matched patients. Because the propensity score analysis could not compare three groups (i.e., LAT, TACE, and BSC), the utility was compared between each treatment and BSC, according to the hazard ratio (HR) of treatment compared to BSC.

\section{Results}

Clinical Factors Associated with Survival in Patients with HCC and C-P Grade C LC

To evaluate which factors contributed to the improvement of OS in patients with HCC and $\mathrm{C}$-P grade $\mathrm{C}$, we analyzed the association between the duration of OS and each clinical parameter. The univariate analysis revealed that a younger age, smaller tumor size, lower AFP level, lower C-P score, lower TNM stage, and receipt of treatment were identified as significant factors contributing to an increased duration of OS ( $p<0.0001$ for each by log-rank test, table 3 ). The status of hepatitis virus infection also showed borderline significance $(\mathrm{p}=0.0424)$.

We subsequently performed a multivariate analysis, which showed that receipt of treatment $(p<0.0001)$, smaller tumor size $(p=0.0002)$, lower AFP levels $(p=0.0010)$, lower TNM stage $(\mathrm{p}<0.0001)$, and lower C-P score $(\mathrm{p}=0.0070)$ were independent contributors to longer survival (see table 4). In a comparison of OS among the BSC, LT, LAT, and TACE groups with $\mathrm{C}-\mathrm{P}$ grade $\mathrm{C}$, the LT group showed the longest OS compared to the LAT $(\mathrm{p}=0.0271)$ and TACE $(\mathrm{p}<0.0001)$ groups, respectively. Conversely, the LAT $(\mathrm{p}<0.0001)$ and TACE $(\mathrm{p}<0.0001)$ groups showed longer OS than the BSC group for each comparison (see fig. 1a). Similarly, in patients within the Milan criteria, the LT group showed the longest OS than the LAT ( $p=0.0079)$ and 
Table 1. Characteristics of patients with HCC in each treatment group with C-P scores of 10 or 11

\begin{tabular}{|c|c|c|c|c|c|}
\hline \multirow[t]{3}{*}{ Background factors } & BSC & LAT & TACE & $\begin{array}{l}\text { Total } \\
n=1040\end{array}$ & p value \\
\hline & $\mathrm{n}=198$ & $\mathrm{n}=218$ & $\mathrm{n}=187$ & $\mathrm{n}=603$ & \\
\hline & No. of Patients & No. of Patients & No. of Patients & No. of Patients & \\
\hline \multicolumn{6}{|l|}{ Age (years) } \\
\hline$<60$ & 44 & 77 & 61 & 182 & 0.009 \\
\hline$\geq 60$ & 154 & 141 & 126 & 421 & \\
\hline \multicolumn{6}{|l|}{ Sex } \\
\hline Male & 130 & 140 & 114 & 384 & 0.611 \\
\hline Female & 68 & 78 & 73 & 219 & \\
\hline \multicolumn{6}{|c|}{ Hepatitis B and virological status } \\
\hline $\mathrm{B}-, \mathrm{C}+$ & 128 & 142 & 119 & 389 & 0.960 \\
\hline $\mathrm{B}+, \mathrm{C}-$ & 24 & 25 & 27 & 76 & \\
\hline $\mathrm{B}+, \mathrm{C}+$ & 3 & 4 & 4 & 11 & \\
\hline $\mathrm{B}-, \mathrm{C}-$ & 38 & 42 & 31 & 111 & \\
\hline \multicolumn{6}{|c|}{ Maximum tumor size $(\mathrm{cm})$} \\
\hline$\leq 2.0$ & 96 & 132 & 84 & 312 & 0.009 \\
\hline $2.1-3.0$ & 74 & 68 & 71 & 213 & \\
\hline $3.1-5.0$ & 28 & 18 & 32 & 78 & \\
\hline \multicolumn{6}{|l|}{ No.of tumors } \\
\hline 1 & 144 & 164 & 116 & 424 & 0.011 \\
\hline$\geq 2$ & 54 & 54 & 71 & 179 & \\
\hline \multicolumn{6}{|l|}{$\mathrm{AFP}(\mathrm{ng} / \mathrm{ml})$} \\
\hline$\leq 200$ & 93 & 114 & 117 & 324 & $<0.0001$ \\
\hline$>200$ & 119 & 29 & 75 & & \\
\hline \multicolumn{6}{|l|}{ TNM stage } \\
\hline I & 71 & 102 & 50 & 223 & $<0.0001$ \\
\hline II & 98 & 92 & 100 & 290 & \\
\hline III & 29 & 24 & 37 & 90 & \\
\hline
\end{tabular}

TACE $(\mathrm{p}=0.0010)$ groups, respectively. On the other hand, the LAT $(\mathrm{p}<0.0001)$ and TACE $(p<0.0001)$ groups showed longer OS than the BSC group for each comparison (see fig. $1 \mathrm{~b}$ ).

To determine whether locoregional treatment for HCC showed benefit regardless of the baseline C-P score, we further excluded the LT focusing on the impact of LAT and TACE. We also conducted separate survival analyses in both the lower C-P score and higher C-P score groups. In the lower C-P score group, both the LAT and TACE groups showed longer OS than the BSC group ( $\mathrm{p}<0.0001$ for both LAT and TACE groups; see fig. $2 \mathrm{a}$ ), suggesting that these locoregional treatments might have a survival benefit for patients with HCC and C-P score 10 or 11 . The median OS (95\% confidence interval [CI]) of patients who received BSC and locoregional treatments were 4.0 months (range 2.9-5.1 months) for the BSC group, 26.0 months (range 22.4-29.6 months) for the LAT group, and 17.0 months (range 14.6-19.4 months) for the TACE group, respectively ( $p<0.0001$ for each comparison; see fig. $2 \mathrm{a}$ ).

Similarly, in patients with HCC with a higher C-P score, both the LAT and TACE groups had longer OS than the BSC group. The median OS (95\% CI) of patients who received BSC and locoregional treatment groups were 2.0 months (range 1.5-2.5 months) for the BSC group, 11.0 months (range 9.4-12.6 months) for the LAT group, and 14.0 months (range 11.9-16.1 months) for the TACE group, respectively ( $\mathrm{p}<0.0001$ for each comparison except for LAT vs. TACE; see fig. 2b). 
Table 2. Characteristics of patients with HCC in each treatment group with C-P sores of 12-15

\begin{tabular}{|c|c|c|c|c|c|}
\hline \multirow[t]{3}{*}{ Background factors } & BSC & LAT & TACE & $\begin{array}{l}\text { Total } \\
\mathrm{n}=1040\end{array}$ & $\mathrm{p}$ value \\
\hline & $n=93$ & $n=22$ & $\mathrm{n}=28$ & \multirow{2}{*}{\multicolumn{2}{|c|}{$\begin{array}{l}n=143 \\
\text { No. of Patients }\end{array}$}} \\
\hline & No. of Patients & No. of Patients & No. of Patients & & \\
\hline \multicolumn{6}{|l|}{ Age (years) } \\
\hline$<60$ & 26 & 8 & 12 & 46 & \multirow[t]{2}{*}{0.320} \\
\hline$\geq 60$ & 67 & 14 & 16 & 97 & \\
\hline \multicolumn{6}{|l|}{ Sex } \\
\hline Male & 60 & 17 & 19 & 96 & \multirow[t]{2}{*}{0.516} \\
\hline Female & 33 & 5 & 9 & 47 & \\
\hline \multicolumn{6}{|c|}{ Hepatitis B and C virological status } \\
\hline $\mathrm{B}-, \mathrm{C}+$ & 47 & 14 & 19 & 80 & \multirow[t]{4}{*}{0.134} \\
\hline $\mathrm{B}+, \mathrm{C}-$ & 15 & 3 & 3 & 21 & \\
\hline $\mathrm{B}+, \mathrm{C}+$ & 1 & 1 & 1 & 3 & \\
\hline $\mathrm{B}-, \mathrm{C}-$ & 24 & 4 & 5 & 33 & \\
\hline \multicolumn{6}{|c|}{ Maximum tumor size $(\mathrm{cm})$} \\
\hline$\leq 2.0$ & 38 & 13 & 10 & 61 & \multirow[t]{3}{*}{0.489} \\
\hline $2.1-3.0$ & 35 & 7 & 12 & 54 & \\
\hline $3.1-5.0$ & 20 & 2 & 6 & 28 & \\
\hline \multicolumn{6}{|l|}{ No. of tumors } \\
\hline 1 & 66 & 18 & 20 & 104 & \multirow[t]{2}{*}{0.392} \\
\hline$\geq 2$ & 27 & 4 & 8 & 39 & \\
\hline \multicolumn{6}{|l|}{$\overline{\mathrm{AFP}}(\mathrm{ng} / \mathrm{ml})$} \\
\hline$\leq 200$ & 47 & 7 & 25 & 79 & \multirow[t]{2}{*}{0.090} \\
\hline$>200$ & 54 & 7 & 12 & 73 & \\
\hline \multicolumn{6}{|l|}{ TNM stage } \\
\hline I & 24 & 10 & 6 & 40 & \multirow[t]{3}{*}{0.362} \\
\hline II & 56 & 11 & 18 & 85 & \\
\hline III & 13 & 1 & 4 & 18 & \\
\hline
\end{tabular}

Survival Benefit of Locoregional Treatment for HCC in Patients with Lower and Higher C-P Scores

We also conducted a multivariate analysis to determine the independent variables that had an effect on the duration of OS in patients with HCC and lower C-P scores. Notably, a longer OS was observed even in patients who received locoregional treatment compared to those who received BSC ( $p<0.0001$ for all variables; HR and 95\% CI: 0.338 and $0.25-0.45$ for LAT vs. BSC, and 0.462 and $0.36-0.58$ for TACE vs. BSC, respectively). Tumor size ( $\leq 2.0 \mathrm{~cm}$ vs. $\geq 3.1 \mathrm{~cm})$ and the AFP level were also associated with improved OS, with p values of $<0.0001$ (HR 0.595 ; 95\% CI, 0.45-0.77) and 0.0004 (HR 0.665; 95\% CI, 0.53-0.83), respectively (table 5).

For the patients with higher C-P scores, LAT and TACE also had a survival benefit ( $\mathrm{p}=0.0014$, HR and 95\% CI=0.361 and 0.17-0.68 for LAT vs. BSC, $\mathrm{p}=0.0018, \mathrm{HR}$ and $95 \%$ $\mathrm{CI}=0.517$ and 0.33-0.78 for TACE vs. BSC, respectively). Lower AFP level were also associated with improved OS, with a p value of 0.0008 (HR=0.533; 95\% CI, 0.37-0.76). However, tumor size ( $\leq 2.0$ vs. $\geq 3.1$ ) showed borderline significance on survival with a p value of 0.0664 (HR=0.662; 95\% CI, 0.35-1.03; table 6). 
Table 3. Univariate analysis of risk factors for survival in patients with HCC with C-P grade C LC

\begin{tabular}{|c|c|c|c|c|c|c|}
\hline \multirow[t]{2}{*}{ Background factor } & \multirow{2}{*}{$\begin{array}{l}n=1344 \\
\text { No. of } \\
\text { patients }\end{array}$} & \multirow{2}{*}{$\begin{array}{l}\text { Median } \\
\text { survival time } \\
\text { (months) }\end{array}$} & \multicolumn{2}{|c|}{ Survival rate (\%) } & \multirow[b]{2}{*}{ 5-year } & \multirow[t]{2}{*}{$\mathrm{p}$ value } \\
\hline & & & 1-year & 3-year & & \\
\hline \multicolumn{7}{|l|}{ Age (years) } \\
\hline$<60$ & 432 & 18 & 57.9 & 31.1 & 19.9 & $<0.0001$ \\
\hline$\geq 60$ & 911 & 9 & 43.3 & 14.9 & 5.1 & \\
\hline \multicolumn{7}{|l|}{ Sex } \\
\hline Male & 897 & 11 & 48.0 & 18.8 & 7.4 & 0.5627 \\
\hline Female & 447 & 11 & 47.9 & 21.1 & 14.4 & \\
\hline \multicolumn{7}{|c|}{ Hepatitis B and C virological status } \\
\hline $\mathrm{B}-, \mathrm{C}+$ & 803 & 11 & 46.2 & 18.7 & 8.6 & 0.0424 \\
\hline $\mathrm{B}+, \mathrm{C}-$ & 204 & 12 & 49.1 & 24.4 & - & \\
\hline $\mathrm{B}+, \mathrm{C}+$ & 25 & 16 & 59.4 & 12.4 & - & \\
\hline $\mathrm{B}-, \mathrm{C}-$ & 262 & 13 & 51.2 & 21.2 & 6.8 & \\
\hline \multicolumn{7}{|l|}{ Maximum tumor size $(\mathrm{cm})$} \\
\hline$\leq 2.0$ & 441 & 15 & 57.3 & 36.9 & 26.4 & $<0.0001$ \\
\hline $2.1-3.0$ & 335 & 16 & 57.2 & 31.7 & 18.8 & \\
\hline$>3.1$ & 568 & 4 & 28.2 & 13.1 & 7.9 & \\
\hline \multicolumn{7}{|l|}{ No. of tumors } \\
\hline Solitary & 768 & 11 & 48.3 & 21.4 & 10.5 & 0.1591 \\
\hline Multiple & 576 & 11 & 47.5 & 17.0 & 8.1 & \\
\hline \multicolumn{7}{|l|}{$\mathrm{AFP}(\mathrm{ng} / \mathrm{ml})$} \\
\hline$\leq 200$ & 448 & 13 & 53.3 & 27.4 & 18.0 & \\
\hline$>200$ & 315 & 9 & 26.5 & 14.0 & 6.3 & $<0.0001$ \\
\hline \multicolumn{7}{|l|}{ Treatment } \\
\hline Yes (LT, LAT and TACE) & 541 & 18 & 62.4 & 27.4 & 13.5 & $<0.0001$ \\
\hline No (BSC) & 803 & 3 & 25.7 & 6.9 & 2.4 & \\
\hline \multicolumn{7}{|l|}{ C-P score } \\
\hline 10 or 11 & 1040 & 13 & 52.5 & 20.9 & 9.40 & $<0.0001$ \\
\hline $12-15$ & 304 & 5 & 32.7 & 15.0 & - & \\
\hline \multicolumn{7}{|l|}{ TNM stage } \\
\hline I & 283 & 11 & 59.2 & 28.1 & 14.7 & $<0.0001$ \\
\hline II & 496 & 10 & 48.9 & 18.9 & 8.4 & \\
\hline III & 301 & 9 & 48.8 & 12.9 & 5.1 & \\
\hline IV & 264 & 11 & 45.1 & 16.5 & 7.8 & \\
\hline
\end{tabular}

Locoregional Treatment of HCC Showed a Survival Benefit in Cases with C-P Score 10 or 11 by Propensity Score Analyses

The results of the multivariate analysis may be attributed to selection bias of the treatment based upon differences in clinical background inherent to retrospective analyses. As a consequence, we performed analyses using an unbiased method to confirm the benefit of locoregional treatment. Accordingly, we applied propensity score analyses between the BSC and locoregional treatment groups (i.e., LAT and TACE), specifically for HCC cases that met the Milan criteria for tumor status. After propensity score matching, there were no significant differences in the background characteristics between BSC and LAT groups (table 7), as well as between the BSC and TACE groups (table 8), suggesting that these were suitable cohorts for the unbiased analyses. 
Table 4. Multivariate analysis of risk factors for survival in patients with C-P grade C LC

\begin{tabular}{|c|c|c|c|}
\hline Variable & HR & $95 \%$ CI & $\mathrm{p}$ value \\
\hline \multicolumn{4}{|l|}{ Treatment } \\
\hline No & 1 & - & - \\
\hline Yes (LT, LAT, or TACE) & 0.406 & $0.33-0.49$ & $<0.0001$ \\
\hline \multicolumn{4}{|l|}{ Maximum tumor size $(\mathrm{cm})$} \\
\hline$>3.1$ & 1 & - & - \\
\hline $2.1-3.0$ & 0.536 & $0.43-0.67$ & \\
\hline$\leq 2.0$ & 0.618 & $0.38-0.50$ & 0.0002 \\
\hline \multicolumn{4}{|l|}{ Age (years) } \\
\hline$\geq 60$ & 1 & - & - \\
\hline$<60$ & 0.847 & $0.69-1.02$ & 0.0923 \\
\hline \multicolumn{4}{|l|}{$\mathrm{AFP}(\mathrm{ng} / \mathrm{ml})$} \\
\hline$>200$ & 1 & & \\
\hline$\leq 200$ & 0.729 & $0.60-0.88$ & 0.0010 \\
\hline \multicolumn{4}{|l|}{ C-P score } \\
\hline $12-15$ & 1 & - & - \\
\hline 10 or 11 & 0.756 & $0.62-0.92$ & 0.0070 \\
\hline \multicolumn{4}{|l|}{ TNM } \\
\hline IV & 1 & & \\
\hline III & 0.594 & $0.45-0.77$ & \\
\hline II & 0.538 & $0.42-0.68$ & \\
\hline $\mathrm{I}$ & 0.524 & $0.35-0.78$ & $<0.0001$ \\
\hline
\end{tabular}

After matching, 124 pairs of patients were eligible for the comparison of OS between the BSC and LAT groups in the cohort of C-P score 10 or 11 (table 7); the median followup period and $25^{\text {th }}-75^{\text {th }}$ percentiles are as follows: 11.0 months and $15.1 \pm 12.9$ months for the LAT group and 7.0 months and 10.6 \pm 12.0 months for the BSC group, respectively. Importantly, patients who underwent LAT showed a lower risk of death than did patients who underwent BSC ( $\mathrm{p}=0.0014, \mathrm{HR}=0.568 ; 95 \% \mathrm{CI}, 0.40-0.80$ : fig. 3a). The 1-, 2-, and 3-year OS rates of the BSC and LAT groups were $53.1 \%, 31.4 \%$, and $15.0 \%$, versus $71.9 \%, 58.5 \%$, and $36.3 \%$, respectively. Similarly, 127 pairs of patients were eligible for OS comparison between the BSC and TACE groups (table 8). The results indicated that the TACE group had a longer OS than the BSC group, even after propensity score matching (median follow-up period and $25^{\text {th }}-75^{\text {th }}$ percentiles: 7.0 months and $10.2 \pm 11.6$ months for the TACE group and 10.0 months and 14.7 \pm 13.9 months for the BSC group, respectively; fig. 3b). The HR of receiving TACE for patient survival was $0.691(95 \% \mathrm{CI}, 0.50-0.96$; $\mathrm{p}=0.0289)$ compared to BSC. The 1-, 2-, and 3 -year OS rates of the BSC and TACE groups were $56.9 \%, 33.8 \%$, and $15.0 \%$, versus $63.8 \%$, $39.9 \%$, and $22.9 \%$, respectively.

Assessment of Survival Benefit of Locoregional Treatment for HCC by Propensity Score Matching Analyses in Cases with C-P Score 12-15

We also performed propensity analyses for patients with HCC and C-P scores of 12-15. After propensity score matching, 19 patients were eligible for the BSC versus LAT group analysis, and 49 patients were eligible for the BSC versus TACE group analysis. On comparison of OS between locoregional treatment groups and the BSC group, there were no significant differences for OS duration between the LAT and BSC groups $(\mathrm{p}=0.201, \mathrm{HR}=0.601 ; 95 \% \mathrm{CI}$, 


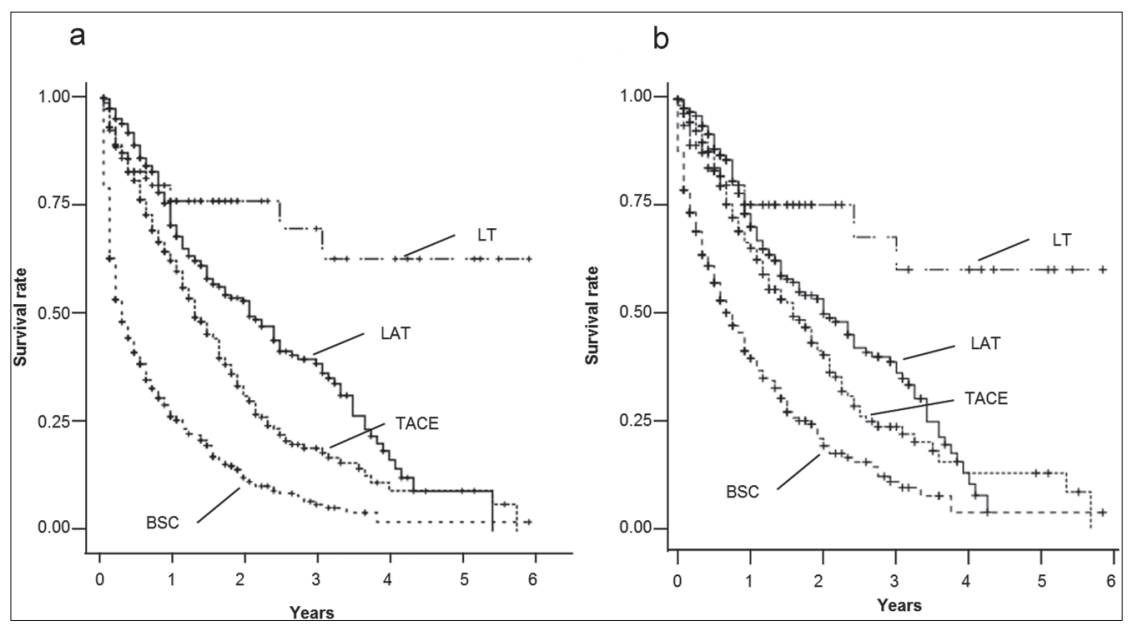

Fig. 1. a A comparison of OS among the BSC, LT, LAT, and TACE groups with C-P grade C. Patients who underwent LT, LAT, and TACE had significantly longer OS than patients who received BSC $(p<0.0001)$. Moreover, there was significant difference in OS between the LT and LAT groups $(\mathrm{p}=0.0271)$ as well as the LT and TACE groups ( $\mathrm{p}<0.0001)$. b A comparison of OS among the BSC, LT, LAT, and TACE groups with $\mathrm{C}-\mathrm{P}$ grade $\mathrm{C}$ within the Milan criteria. The patients who underwent LT, LAT, and TACE had significantly longer OS than patients who received BSC $(\mathrm{p}<0.0001)$. The significant difference of OS was observed between the LT and LAT groups ( $p=0.0079)$ as well as the LT and TACE groups $(p=0.0010)$.

0.27-1.36; fig. 3c). Similarly, there were no significant differences for OS duration between the TACE and the BSC groups ( $\mathrm{p}=0.0549$, HR=0.626; 95\% CI, 0.38-1.03; fig. 3d).

\section{Discussion}

The prognosis of HCC with decompensated LC is still unsatisfactory, and LT is the only recommended treatment for patients with HCC and C-P grade C. However, even in patients with HCC meeting the Milan criteria, LT might not be applicable because of the shortage of donor livers. Conversely, the recent developments of novel therapeutic devices help to achieve minimal deterioration of liver function after locoregional treatment [24-27]. From this perspective, it is necessary to re-evaluate the efficacy of locoregional treatments for HCC with decompensated LC, which has been a controversial issue to date. Here, we demonstrate that the locoregional treatments can be effectively used for the treatment of HCC with decompensated LC if the C-P score is 11 or less.

In the present study, the univariate and multivariate analyses revealed that smaller tumor size, lower C-P score, lower serum AFP level, lower TNM stage and receipt of non-surgical HCC treatment were significant factors contributing to an increase in OS. This suggests that these treatments may improve the survival of patients with HCC and C-P grade C. The LT group showed a significantly longer OS than locoregional treatment groups as previously reported $[11,17,28]$. Among patients with a lower C-P score, a longer OS was also observed in patients who underwent locoregional treatment compared to patients who received BSC. For patients with higher C-P scores, LAT, and TACE were also identified as carrying a survival benefit, suggesting that locoregional treatment for HCC may contribute to improvement in OS in these cases.

However, as is inherent with retrospective analyses, the bias of treatment selection can lead to unexpected results regarding the contribution of locoregional treatment to an in- 


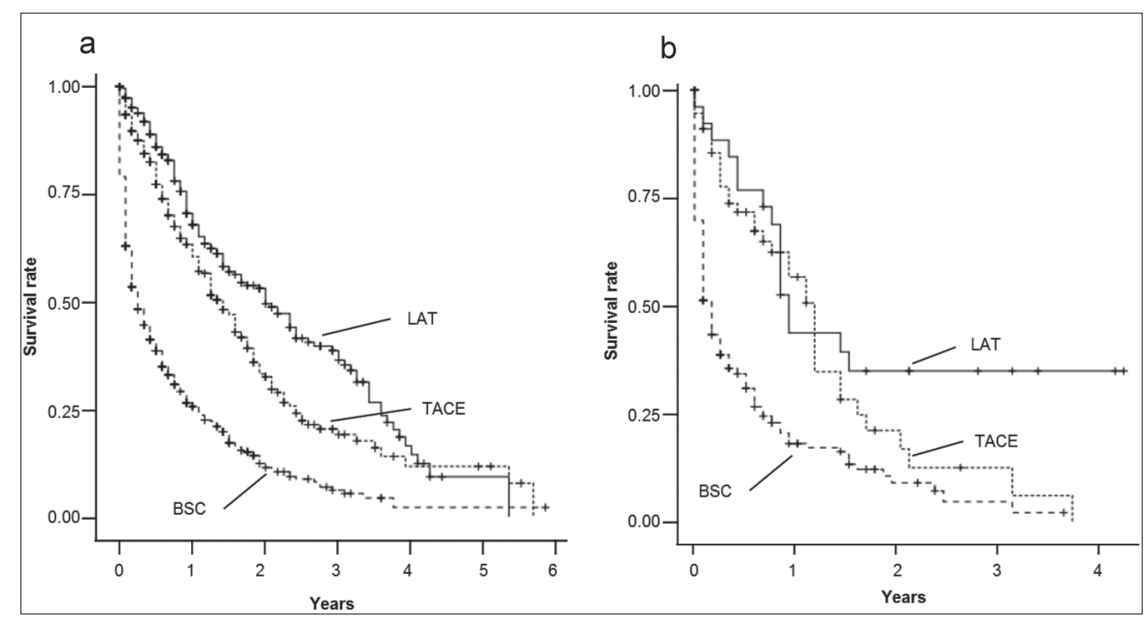

Fig. 2. a A comparison of OS among the BSC, LAT, and TACE groups with C-P scores of 10 or 11 . Each Kaplan-Meier survival curve represents the OS of patients who underwent LAT, TACE, and BSC. The patients who underwent LAT or TACE had significantly longer OS than patients who received BSC $(\mathrm{p}<0.0001)$. b A comparison of OS among the BSC, LAT, and TACE groups with C-P scores of 12-15. The Kaplan-Meier survival curves indicate that patients who underwent LAT or TACE had significantly longer OS than patients who received BSC $(\mathrm{p}<0.0001)$.

Table 5. Multivariate analysis of risk factors for survival in patients with a C-P score of 10 or 11

\begin{tabular}{|c|c|c|c|}
\hline Variable & HR & $95 \%$ CI & $\mathrm{p}$ value \\
\hline \multicolumn{4}{|l|}{ Treatment } \\
\hline LAT vs. BSC & 0.338 & $0.25-0.45$ & $<0.0001$ \\
\hline TACE vs. BSC & 0.462 & $0.36-0.58$ & $<0.0001$ \\
\hline \multicolumn{4}{|l|}{ Age (years) } \\
\hline$<60$ vs. $\geq 60$ & 0.949 & $0.74-1.19$ & 0.6679 \\
\hline \multicolumn{4}{|c|}{ Maximum tumor size $(\mathrm{cm})$} \\
\hline$\leq 2.0$ vs. $2.1-3.0$ & 1.18 & $0.88-1.58$ & 0.2590 \\
\hline$\leq 2.0$ vs. $\geq 3.1$ & 0.595 & $0.45-0.77$ & $<0.0001$ \\
\hline \multicolumn{4}{|l|}{$\operatorname{AFP}(\mathrm{ng} / \mathrm{ml})$} \\
\hline$\leq 200$ vs. $>200$ & 0.665 & $0.53-0.83$ & 0.0004 \\
\hline \multicolumn{4}{|l|}{ Number of tumors } \\
\hline solitary vs. multiple & 0.985 & $0.79-1.21$ & 0.8935 \\
\hline
\end{tabular}

creased duration of OS. For example, age, background liver function, and the number and size of tumors may affect the selection of treatment. Therefore, we further applied a less-biased method using propensity score matching, and normalized the patients' backgrounds. After the matching, locoregional treatment also showed a significant association with longer survival as compared to the BSC groups in the lower C-P score group. Although there has been a lack of evidence regarding the benefit of locoregional treatment in patients with HCC and C-P grade $\mathrm{C}$, refined techniques using new devices for RFA and TACE may contribute to an improvement in survival, even in patients with HCC that have decompensated LC. To the contrary, in the cohort of higher C-P scores of 12-15, locoregional treatment did not produce a survival benefit, suggesting that LT is the only current treatment showing survival benefit. To further confirm the ineligibility of locoregional treatment in the C-P score 12-15 group, we analyzed the intragroup causes of death as follows: 22 of 44 patients (50\%) in the locoregional treatment group 
Table 6. Multivariate analysis of risk factors for survival in patients with a C-P score of 12-15

\begin{tabular}{llll}
\hline Variable & HR & $95 \%$ CI & p Value \\
$\begin{array}{l}\text { Treatment } \\
\quad \text { LAT vs. BSC }\end{array}$ & 0.361 & $0.17-0.68$ & 0.0014 \\
$\quad$ TACE vs. BSC & 0.517 & $0.33-0.78$ & 0.0018 \\
\hline $\begin{array}{l}\text { Age (years) } \\
\quad \text { < } 60 \text { vs. } \geq 60\end{array}$ & 0.89 & $0.59-1.30$ & 0.5674 \\
$\begin{array}{l}\text { AFP (ng } / \mathrm{ml}) \\
\quad \leq 200 \text { vs. }>200\end{array}$ & 0.533 & $0.37-0.76$ & 0.0008 \\
$\begin{array}{l}\text { Maximum tumor size (cm) } \\
\quad \leq 2.0 \text { vs. } 2.1-3.0\end{array}$ & 0.957 & $0.52-1.73$ & 0.8879 \\
$\quad \leq 2.0$ vs. $\geq 3.1$ & 0.622 & $0.35-1.03$ & 0.0664 \\
\hline
\end{tabular}

died of hepatic failure and 13 patients (29.5\%) died of cancer; 93 of 136 patients $(50.2 \%)$ in the BSC group died of hepatic failure and 55 patients (40.4\%) died of cancer. This supports the idea that the leading cause of death of the patients with C-P scores of 12-15 was hepatic failure, and cancer-related death was not the main cause even in the BSC group. Therefore it is conceivable that any intervention without improvement of liver decompensation is unlikely to be tolerated, or it will affect the survival for this patient group.

Although the data suggest a survival benefit of locoregional treatment in patients with HCC along with lower scores of C-P grade C, there are certain limitations in this study. First, as the nature of retrospective studies, there may be bias regarding the effect of treatment on OS, even after propensity score matching. For example, the source database is potentially flawed, since only stronger/healthier C-P grade C patients would see a physician and hence become registered. Moreover, significant selection bias occurred at the time of treatment decisions, because stronger/healthier patients tended to be treated. Second, propensity score analyses were performed only for patients with HCC within the Milan criteria in terms of tumor status. Therefore, a treatment benefit for patients with HCC beyond these criteria was not identified in this study. Third, the analysis did not include performance status, a factor that may impact on survival in patients with HCC. Although it was possible that the majority of the patients included in this study should be of a performance status of 0 or 1 , the effect of performance status on survival in the treatment of HCC also needs to be confirmed in the future. However, even with these limitations, the results of this study provide sample evidence for the development of future prospective studies.

In conclusion, we provide evidence of a treatment benefit with LAT and TACE in patients with HCC within the Milan criteria and with C-P scores of 10 or 11 . The results presented here are of clinical importance because BSC is the only recommended therapy in patients with HCC who have deterioration in liver function. Our data indicate that LAT or TACE could be used as a salvage treatment if LT is not applicable. 
Table 7. Comparison of patient characteristics between the BSC and LAT groups with C-P score 10 or 11 , matched by propensity score.

\begin{tabular}{|c|c|c|c|}
\hline Background factors & $\begin{array}{l}\text { BSC } \\
n=124 \\
\text { No. of Patients }\end{array}$ & $\begin{array}{l}\text { LAT } \\
n=124 \\
\text { No. of Patients }\end{array}$ & p value \\
\hline \multicolumn{4}{|l|}{ Age (years) } \\
\hline$<60$ & 35 & 35 & 1 \\
\hline$\geq 60$ & 89 & 89 & \\
\hline \multicolumn{4}{|l|}{ Sex } \\
\hline Male & 80 & 75 & 0.5119 \\
\hline Female & 44 & 49 & \\
\hline \multicolumn{4}{|c|}{ Hepatitis B and C virological status } \\
\hline $\mathrm{B}-, \mathrm{C}+$ & 85 & 83 & 0.7645 \\
\hline $\mathrm{B}+, \mathrm{C}-$ & 14 & 13 & \\
\hline $\mathrm{B}+, \mathrm{C}+$ & 1 & 3 & \\
\hline $\mathrm{B}-, \mathrm{C}-$ & 20 & 22 & \\
\hline \multicolumn{4}{|c|}{ Maximum tumor size $(\mathrm{cm})$} \\
\hline$\leq 2$ & 69 & 72 & 0.8605 \\
\hline $2.1-3.0$ & 47 & 43 & \\
\hline 3.1-5.0 & 8 & 9 & \\
\hline \multicolumn{4}{|l|}{ No. of tumors } \\
\hline 1 & 91 & 90 & 0.8863 \\
\hline $2-3$ & 33 & 34 & \\
\hline \multicolumn{4}{|l|}{ TNM stage } \\
\hline I & 52 & 54 & 0.9636 \\
\hline II & 56 & 54 & \\
\hline III & 16 & 16 & \\
\hline \multicolumn{4}{|l|}{ Bilirubin (mg/dL) } \\
\hline$<2.0$ & 31 & 27 & 0.8303 \\
\hline $2.0-3.0$ & 41 & 42 & \\
\hline$>3.0$ & 52 & 55 & \\
\hline \multicolumn{4}{|l|}{ Albumin (g/dL) } \\
\hline$>3.5$ & 0 & 1 & 0.5694 \\
\hline $2.8-3.5$ & 46 & 43 & \\
\hline$<2.8$ & 78 & 80 & \\
\hline \multicolumn{4}{|l|}{ PT (\%) } \\
\hline$>70$ & 4 & 7 & 0.645 \\
\hline $40-70$ & 107 & 105 & \\
\hline$<40$ & 13 & 12 & \\
\hline \multicolumn{4}{|l|}{ Ascites } \\
\hline None & 44 & 40 & 0.86458 \\
\hline Responsive & 53 & 56 & \\
\hline Unresponsive & 27 & 28 & \\
\hline \multicolumn{4}{|l|}{ Encephalopathy } \\
\hline None & 69 & 70 & 0.9361 \\
\hline Mild & 36 & 37 & \\
\hline Coma & 19 & 17 & \\
\hline
\end{tabular}


Table 8. Comparison of patient characteristics between the BSC and TACE groups with C-P score 10 or 11, matched by propensity score.

\begin{tabular}{|c|c|c|c|}
\hline Background factors & $\begin{array}{l}\text { BSC } \\
n=127 \\
\text { No. of Patients }\end{array}$ & $\begin{array}{l}\text { TACE } \\
n=127 \\
\text { No. of Patients }\end{array}$ & $\mathrm{p}$ value \\
\hline \multicolumn{4}{|l|}{ Age (years) } \\
\hline$<60$ & 38 & 32 & 0.3995 \\
\hline$\geq 60$ & 89 & 95 & \\
\hline \multicolumn{4}{|l|}{ Sex } \\
\hline Male & 81 & 79 & 0.7949 \\
\hline Female & 46 & 48 & \\
\hline \multicolumn{4}{|c|}{ Hepatitis B and C virological status } \\
\hline $\mathrm{B}-, \mathrm{C}+$ & 83 & 86 & 0.4087 \\
\hline $\mathrm{B}+, \mathrm{C}-$ & 13 & 16 & \\
\hline $\mathrm{B}+, \mathrm{C}+$ & 2 & 0 & \\
\hline $\mathrm{B}-, \mathrm{C}-$ & 26 & 21 & \\
\hline \multicolumn{4}{|c|}{ Maximum tumor size $(\mathrm{cm})$} \\
\hline$\leq 2$ & 58 & 58 & 0.9828 \\
\hline $2.1-3.0$ & 48 & 49 & \\
\hline $3.1-5.0$ & 21 & 20 & \\
\hline \multicolumn{4}{|l|}{ No. of tumors } \\
\hline 1 & 84 & 85 & 0.8942 \\
\hline $2-3$ & 43 & 42 & \\
\hline \multicolumn{4}{|l|}{ TNM stage } \\
\hline I & 39 & 36 & 0.6549 \\
\hline II & 64 & 71 & \\
\hline III & 24 & 20 & \\
\hline \multicolumn{4}{|l|}{ Bilirubin (mg/dL) } \\
\hline$<2.0$ & 35 & 31 & 0.8488 \\
\hline $2.0-3.0$ & 43 & 45 & \\
\hline$>3.0$ & 49 & 51 & \\
\hline \multicolumn{4}{|l|}{ Albumin (g/dL) } \\
\hline$>3.5$ & 2 & 3 & 0.8886 \\
\hline $2.8-3.5$ & 41 & 42 & \\
\hline$<2.8$ & 84 & 82 & \\
\hline \multicolumn{4}{|l|}{ PT (\%) } \\
\hline$>70$ & 7 & 10 & 0.7462 \\
\hline $40-70$ & 106 & 104 & \\
\hline$<40$ & 14 & 13 & \\
\hline \multicolumn{4}{|l|}{ Ascites } \\
\hline None & 34 & 32 & 0.8772 \\
\hline Responsive & 50 & 54 & \\
\hline Unresponsive & 43 & 41 & \\
\hline \multicolumn{4}{|l|}{ Encephalopathy } \\
\hline None & 76 & 75 & 0.8867 \\
\hline Mild & 43 & 42 & \\
\hline Coma & 8 & 10 & \\
\hline
\end{tabular}




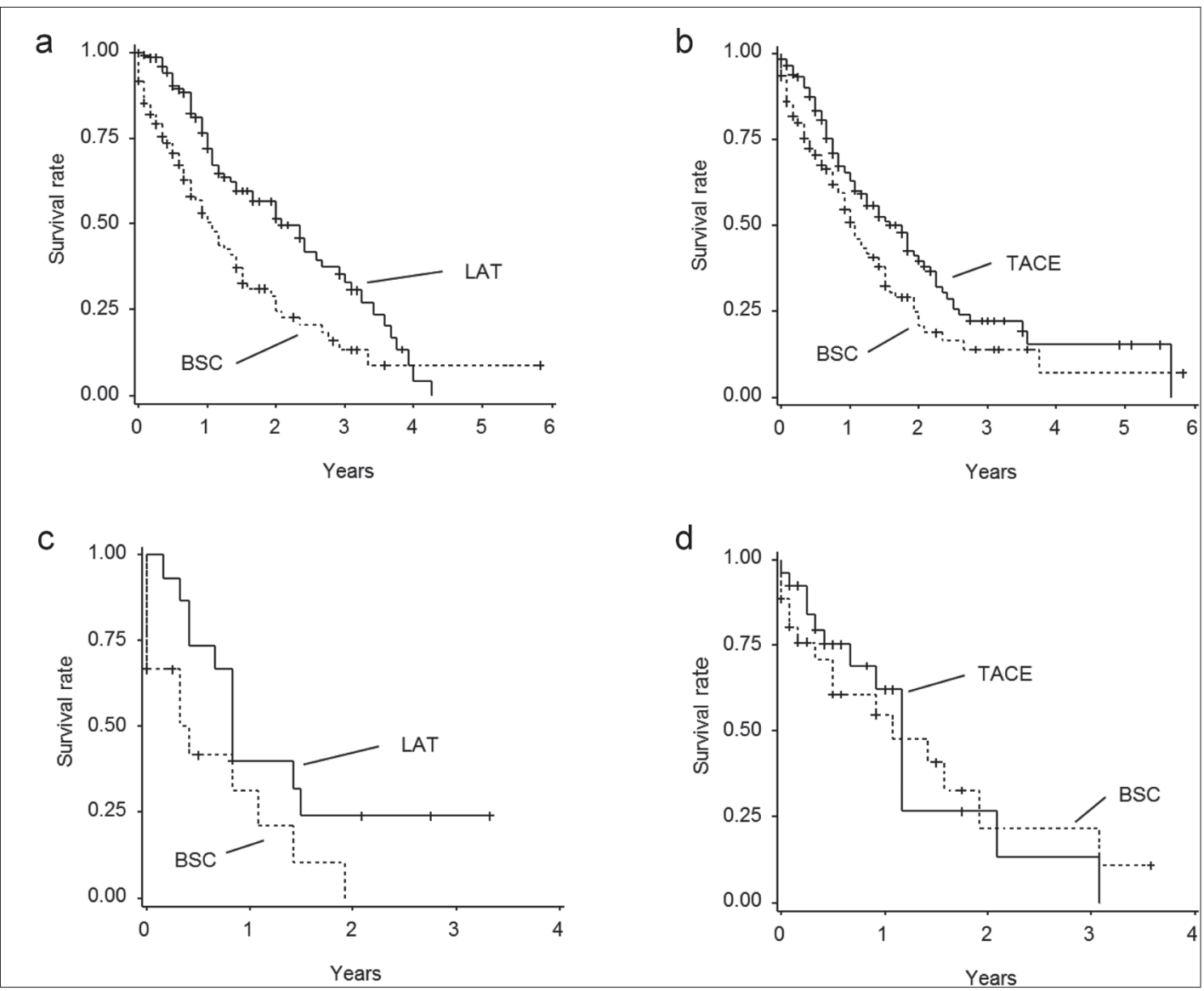

Fig. 3. a A comparison of OS between the BSC and LAT groups with C-P scores of 10 or 11, after matching patient backgrounds using propensity score analysis. The Kaplan-Meier curve shows that the LAT group had a lower risk of death than the BSC group (HR 0.568; 95\% CI, 0.40-0.80; $\mathrm{p}=0.0014$ ). b A comparison of OS between the BSC and TACE groups with C-P scores of 10 or 11, after matching patient backgrounds using propensity score analysis. The TACE group had a lower risk of death than the BSC group (HR 0.691; 95\% CI, 0.50-0.96; $\mathrm{p}=0.0289$ ). $\mathbf{c}$ A comparison of OS between the BSC and LAT groups with C-P scores of 12-15, after matching patient backgrounds using propensity score analysis. The LAT group had a lower risk of death than the BSC group (HR 0.601; 95\% CI, 0.27-1.36; $\mathrm{p}=0.201$ ). $\mathbf{d}$ A comparison of OS between the BSC and TACE groups with C-P scores of 12-15, after matching patient background s using propensity score analysis. The TACE group had a lower risk of death than the BSC group (HR 0.626; 95\% CI, 0.381.03; $\mathrm{p}=0.0549$ ).

\section{Grant Support}

This work was supported by the Health Labor Sciences Research Grant from The Ministry of Health, Labour and Welfare (H22-Clinical Oncology-General-015), Japan.

\section{Competing Interests}

The authors have no competing interests to declare. 


\section{Author Contributions}

SK, NN, and MK designed the studies, wrote the initial version of the paper, and revised the manuscript. SK, NN, NI, MS, YM, TI, ON, OM, YK, NK, MM, and MK interpreted the data, performed the statistical analyses, and helped with acquisition of data. MK organized collaborations, obtained funding, supervised data collection. SK, NN, NI, MS, YM, TI, ON, OM, YK, NK, MM, and MK helped with acquisition of data.

\section{References}

1 Jemal A, Bray F, Center MM, Ferlay J, Ward E, Forman D: Global cancer statistics. CA Cancer J Clin 2011;61:69-90.

2 Perz JF, Armstrong GL, Farrington LA, Hutin YJ, Bell BP: The contributions of hepatitis B virus and hepatitis C virus infections to cirrhosis and primary liver cancer worldwide. J Hepatol 2006;45:529-538.

3 Infante-Rivard C, Esnaola S, Villeneuve JP: Clinical and statistical validity of conventional prognostic factors in predicting short-term survival among cirrhotics. Hepatology 1987;7:660-664.

4 Kudo M, Chung H, Haji S, Osaki Y, Oka H, Seki T, Kasugai H, Sasaki Y, Matsunaga T: Validation of a new prognostic staging system for hepatocellular carcinoma: the JIS score compared with the CLIP score. Hepatology 2004;40:1396-1405.

5 Kudo M, Izumi N, Kokudo N, Matsui O, Sakamoto M, Nakashima O, Kojiro M, Makuuchi M, HCC Expert Panel of Japan Society of Hepatology: Management of hepatocellular carcinoma in Japan: Consensus-Based Clinical Practice Guidelines proposed by the Japan Society of Hepatology (JSH) 2010 updated version. Dig Dis 2011;29:339-364.

6 Faber W, Sharafi S, Stockmann M, Denecke T, Sinn B, Puhl G, Bahra M, Malinowski MB, Neuhaus P, Seehofer D: Long-term results of liver resection for hepatocellular carcinoma in noncirrhotic liver. Surgery 2013;153:510-517.

7 Lee Cheah Y, K H Chow P: Liver transplantation for hepatocellular carcinoma: an appraisal of current controversies. Liver Cancer 2012;1:183-189.

8 Chan SC: Liver transplantation for hepatocellular carcinoma. Liver Cancer 2013;2:338-344.

9 Chan SC, Sharr WW, Chan AC, Chok KS, Lo CM: Rescue Living-donor Liver Transplantation for Liver Failure Following Hepatectomy for Hepatocellular Carcinoma. Liver Cancer 2013;2:332-337.

10 Belghiti J, Fuks D: Liver resection and transplantation in hepatocellular carcinoma. Liver Cancer 2012;1:71-82.

11 Mazzaferro V, Bhoori S, Sposito C, Bongini M, Langer M, Miceli R, Mariani L: Milan criteria in liver transplantation for hepatocellular carcinoma: an evidence-based analysis of 15 years of experience. Liver Transpl 2011;17(Suppl 2):S44-S57.

12 Lin SM: Local ablation for hepatocellular carcinoma in taiwan. Liver Cancer 2013;2:73-83.

13 Lencioni R: Loco-regional treatment of hepatocellular carcinoma. Hepatology 2010;52:762-773.

14 Llovet JM, Bruix J: Systematic review of randomized trials for unresectable hepatocellular carcinoma: Chemoembolization improves survival. Hepatology 2003;37:429-442.

15 Lencioni R: Chemoembolization in patients with hepatocellular carcinoma. Liver Cancer 2012;1:41-50.

16 Llovet JM, Real MI, Montaña X, Planas R, Coll S, Aponte J, Ayuso C, Sala M, Muchart J, Solà R, Rodés J, Bruix J, Barcelona Liver Cancer Group: Arterial embolisation or chemoembolisation versus symptomatic treatment in patients with unresectable hepatocellular carcinoma: a randomised controlled trial. Lancet 2002;359:1734-1739.

17 Mazzaferro V, Regalia E, Doci R, Andreola S, Pulvirenti A, Bozzetti F, Montalto F, Ammatuna M, Morabito A, Gennari L: Liver transplantation for the treatment of small hepatocellular carcinomas in patients with cirrhosis. N Engl J Med 1996;334:693-699.

18 Kudo M: Treatment of advanced hepatocellular carcinoma with emphasis on hepatic arterial infusion chemotherapy and molecular targeted therapy. Liver Cancer 2012;1:62-70.

19 Nouso K, Ito Y, Kuwaki K, Kobayashi Y, Nakamura S, Ohashi Y, Yamamoto K: Prognostic factors and treatment effects for hepatocellular carcinoma in Child C cirrhosis. Br J Cancer 2008;98:1161-1165.

20 Kudo M, Osaki Y, Matsunaga T, Kasugai H, Oka H, Seki T: Hepatocellular carcinoma in Child-Pugh C cirrhosis: prognostic factors and survival benefit of nontransplant treatments. Dig Dis 2013;31:490-498.

21 Bruix J, Sherman M Practice Guidelines Committee, American Association for the Study of Liver Diseases: Management of hepatocellular carcinoma. Hepatology 2005;42:1208-1236.

22 Izumi N: Diagnostic and treatment algorithm of the Japanese society of hepatology: a consensus-based practice guideline. Oncology 2010;78(Suppl 1):78-86.

23 European Association For The Study Of The Liver European Organisation For Research And Treatment Of Cancer: EASL-EORTC clinical practice guidelines: management of hepatocellular carcinoma. J Hepatol 2012;56:908-943.

24 Kudo M: Real practice of hepatocellular carcinoma in Japan: conclusions of the Japan Society of Hepatology 2009 Kobe Congress. Oncology 2010;78(Suppl 1):180-188. 
25 Minami Y, Kitai S, Kudo M: Treatment response assessment of radiofrequency ablation for hepatocellular carcinoma: usefulness of virtual CT sonography with magnetic navigation. Eur J Radiol 2012;81:e277e280.

26 Takayasu K: Superselective transarterial chemoembolization for hepatocellular carcinoma: recent progression and perspective. Oncology 2011;81(Suppl 1):105-110.

27 Takayasu K, Arii S, Ikai I, Omata M, Okita K, Ichida T, Matsuyama Y, Nakanuma Y, Kojiro M, Makuuchi M, Yamaoka Y, Liver Cancer Study Group of Japan: Prospective cohort study of transarterial chemoembolization for unresectable hepatocellular carcinoma in 8510 patients. Gastroenterology 2006;131:461-469.

28 Tamura S, Sugawara Y, Kokudo N: Living donor liver transplantation for hepatocellular carcinoma: the Japanese experience. Oncology 2011;81(Suppl 1):111-115. 